\title{
A complete impedance analysis of electrochemical cells used as energy sources
}

\author{
P. Slepski • K. Darowicki • E. Janicka • G. Lentka
}

Received: 28 July 2011 /Revised: 4 July 2012 / Accepted: 4 July 2012 / Published online: 2 August 2012

(C) The Author(s) 2012. This article is published with open access at Springerlink.com

\begin{abstract}
A comprehensive description of impedance of electrochemical systems has been presented, along with the assumptions of the method used. In this method, a multisinusoidal current excitation signal is used. The changes of potential of both the electrodes and the potential difference between these electrodes are all registered simultaneously as a function of time. The proposed method offers the possibility of separately determining the instantaneous value of impedance of each electrode as well as the impedance of a twoelectrode system. The short-time Fourier transform of time registers allow the determination of changes in the measured impedance values over time. The method has been successfully verified with an electrical equivalent circuit simulating a non-stationary two-electrode system. The values of the impedance of particular components during operation of the fuel cell under a changing load have been obtained.
\end{abstract}

Keywords Electrochemical impedance spectroscopy . Multisinusoidal perturbation $\cdot$ Electrochemical cells $\cdot$ Fuel cell

P. Slepski $\cdot$ K. Darowicki $\cdot$ E. Janicka $(\bowtie)$

Department of Electrochemistry, Corrosion and Materials

Engineering, Chemical Faculty, Gdansk University of Technology,

11/12 Narutowicza,

80-233 Gdansk, Poland

e-mail: ewa.janicka@hotmail.com

G. Lentka

Department of Optoelectronics and Electronic Systems, Faculty of Electronics, Telecommunications and Informatics, Gdansk University of Technology,

11/12 Narutowicza,

80-233 Gdansk, Poland

\section{Introduction}

An impedance technique has been commonly employed in studies of the electrochemical sources of energy. This technique is used in working conditions of the electrochemical sources in order to determine their technical parameters, including degree of charging [1-6] or operation conditions such as state of health, state of charge, or depth of discharge [7-9], or for optimizing the operating conditions of the fuel cells [10-15]. In this case, impedance measurements are usually carried out in a two-electrode configuration. Impedance studies are also employed to acquire information about the degree of degradation of electrode materials [16-18], intercalation phenomena [19-23], reagent transport [24, 25], hydrogen absorption [26-29], electrode reaction mechanism [30-32], etc. For all of these applications, a three-electrode configuration is generally used.

The main limitation of using the impedance technique in the case of two-electrode as well as three-electrode configuration is that the system is non-stationary. The proper use of a commercial technique such as frequency response analysis (FRA) requires that the system being analyzed does not change while the measurement is carried out. Difficulties arising from the necessity of maintaining the stationarity conditions can be overcome by using multisinusoidal excitation in cooperation with Fourier transform analysis. The advantages of this kind of signal in impedance techniques are as follows:

- Possibility of shortening of time needed for every single impedance spectrum

- Getting averaged impedance spectrum thanks to Fourier transformation's qualities (what is important when the examined system is not stationary)

- Possibility of combining impedance technique with other electrochemical techniques (multisinusoidal signal is superimposed on other signals) 
- Possibility of getting impedance spectra as a function of time or as a function of changes in other parameters (short-time form of Fourier transformation is needed)

- Elimination of disturbances occurring when the frequency of excitation signal is being changed in sequence mode (multisinusoidal signal is a continuous signal)

This way of performing the impedance measurements has been known since the pioneer works of Smith and Creason in the 1970s [33-35]. The development of digital techniques has contributed to the increase of popularity of the method [36-43], and it has been appreciated sufficiently to be introduced to commercial applications (http://www.gamry.com/ App_Notes/PDF/OptiEISAppNote.pdf).

In studies of electrochemical sources of energy, it is also essential to determine the comprehensive impedance evaluation. There are a few papers available on that topic. Furthermore, in those papers, the complete impedance characteristics of the measured systems are obtained by the classical FRA technique, which requires the stationarity of the system during the measurement. Electrochemical cells are not stationary systems: in the case of fuel cells, there is a possibility of maintaining stationary conditions, but this approach significantly limits the amount of information obtained in the measurement as the fuel cells usually work in changing conditions. Considering this, the authors proposed in this study a measurement method that uses additional pseudo-reference electrodes and enables the simultaneous determination of cathode and anode impedance individually as well as total impedance. Additionally, the proposed measurement allows the obtainment of impedance changes of the individual components over the entire operation time, e.g., while charging/discharging, temperature changes, etc., are occurring. Not only is such an approach relatively innovative but it also meets the measurement requirements with regard to assessment of various electrochemical sources of energy.

\section{Theoretical description}

Figure 1 demonstrates the diagram of the investigated system. It can be seen that not only the current and potential between E1 and E2 are measured but also the potential of individual electrodes due to the two independent reference electrodes.

This approach enables the calculation of the independent impedance values of both electrodes as a part of the experiment. The other goal is to eliminate the impedance with resistance-capacitance character which can be caused by separators or membranes commonly used in power cells. In the case of a single reference electrode, the impedance of the separator/membrane is added to the value obtained for one of the analyzed electrodes. It is possible to eliminate

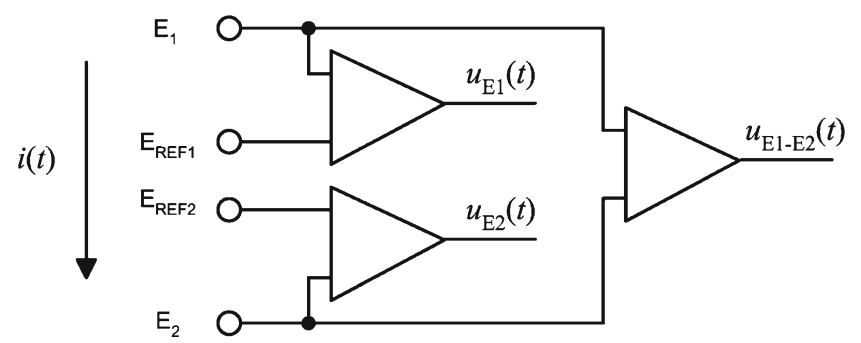

Fig. 1 Diagram of the measurement of the left electrode potential, the right electrode potential, difference of potentials between the left and the right electrodes, and the current flowing between the two electrodes

such circumstances by employing two independent pseudoreference electrodes placed in direct neighborhood of the examined (separated by membrane) electrodes.

The current perturbation presented in Eq. (1) consists of basic sinusoidal signals with constant frequencies and the constant component.

$i(t)=A_{0}+\sum_{n=1}^{n_{\max }} A_{n} \sin \left(2 \pi f_{n} t+\varphi_{n}\right)$

where $A_{0}$ is DC component (polarization), $A_{\mathrm{n}}, f_{n}$, and $\varphi_{\mathrm{n}}$ are the amplitude, the frequency, and the phase of $n$-th component of a multisinusoidal signal, respectively, $n_{\max }$ is the number of components of multisinusoidal signal.

The excitation current flows through the entire system: the left and right electrode. Together with the registration of current changes $i(t)$, the voltage between these electrodes $u_{\mathrm{E} 1-\mathrm{E} 2}(t)$ and the changes of the electrode potential $E_{1}$ and the $E_{2}$ relative to the $E_{\mathrm{REF} 1}$ and the $E_{\mathrm{REF} 2}$ electrode $\left(u_{\mathrm{E} 1}(t)\right.$ and $\left.u_{\mathrm{E} 2}(t)\right)$, respectively, are measured. These parameters change in time due to the multisinusoidal excitation signal $i(t)$ and the variability of the measurement's or object's conditions.

The measured signals are sampled with the defined sampling frequency $f_{\mathrm{s}}$ and they are subsequently quantized using an analog-to-digital converter with a defined resolution (for example, 16 bit). As a result of sampling and quantizing, a discrete representation of signals in the form of four sequences of $N$ samples is obtained, which can be described by a generalized formula:

$x^{m}=x(m \cdot \Delta t)$

where $x$ is the sampled signal: $u_{\mathrm{E} 1}, u_{\mathrm{E} 2}, u_{\mathrm{E} 1-\mathrm{E} 2}, i ; m$ is the sample number $(m=0,1, \ldots N-1), N$ is the total number of samples, $\Delta t$ is the sample spacing $\left(\Delta t=1 / f_{\mathrm{s}}\right)$, and $f_{\mathrm{s}}$ is the sampling frequency.

Using the discrete Fourier transform (DFT) the frequency representation for each sequence of samples can be determined, where its $L$-th line is described by the following general dependencies:

$X^{L}=X(L \cdot \Delta f)=\sum_{m=0}^{N-1} x^{m} \cdot \exp \left(\frac{-j 2 \pi m l}{N}\right)$ 
where $X$ is the frequency representation of the signal: $U_{\mathrm{E} 1-\mathrm{E} 2}, U_{\mathrm{E} 1}, U_{\mathrm{E} 2}$, or $I, L=0,1, \ldots, N-1$ is the $L$-th spectrum line of the signal, $\Delta f=f_{\mathrm{s}} / N=1 / N \Delta t$.

Having complex values of the given voltages earlier, the three complex impedances can be calculated using the general formula:

$Z_{E}^{L}=\frac{U_{E}^{L}}{I^{L}}$

where $Z_{E}^{L}$ is the impedance based on signal: $U_{\mathrm{E} 1-\mathrm{E} 2}, U_{\mathrm{E} 1}$, and $U_{\mathrm{E} 2}$ for $L$-th component of multisinusoidal excitation signal.

The application of the Fourier transform (FT) for the entire data register $(N)$ renders the average value of each impedance for the acquisition time (it results directly from the FT integration properties). The application of the shorttime discrete Fourier transform STDFT [44, 45] allows the acquisition of information on the variability of impedance parameters during the process.

There are significant limitations which need to be taken into consideration while performing the Fourier transform:

- The theoretical upper frequency $f_{\max }$ should be much lower in practice than half the sampling frequency $f_{\mathrm{s}}$ (Nyquist frequency $f_{\mathrm{s}} / 2$ ):

$f_{\max }<\frac{f_{s}}{2}$

- The lower frequency $f_{\min }$ is related to the total data acquisition time $T_{\text {acq }}\left(T_{\text {acq }}=N \Delta t\right)$ as well as requirement (in the basic version of the transform) of registering at least one period of signal which, in a simple way, leads to the dependency:

$f_{\min } \geq \frac{1}{T_{a c q}}$

- Leakage of the impedance spectra obtained using the STFT analysis could be entirely eliminated by maintaining the accurate proportion between a length of the analysis window $\left(T_{\mathrm{w}}\right)$ and period of single frequencies of excitation signal $\left(f_{n}\right)$ :

$T_{W}=k_{n} \frac{1}{f_{n}}$

where $k$ is an integer number.

- Electrochemical systems have non-linear character. Excitation with frequency $f_{n}$ will generate harmonics $\left(2 f_{n}, 3 f_{n} \ldots \mathrm{k} f_{n}\right)$ in response signal. The components of multisinusoidal excitation signal should not be complete multiples of each other in order to reduce the influence of harmonics. When choosing frequencies, one can apply the rule of prime number multiples of the fundamental frequency $\Delta f=1 / T_{\mathrm{W}}$.
In practice, the considered process of impedance measurement consists of a few steps.

In the first step, the examined system is excited with multisinusoidal current signal. At this point, excitation signal as well as global and local voltage response signals are measured (potential of each electrode is measured in relation to its own pseudo-reference electrode). Current signals as well as potential signals are being registered with the same sampling frequency for the whole duration of measurement. Data acquisition system with synchronous sampling in all channels is needed in this case. The use of a system with multiplexer will introduce additional phase shifts.

The second step is fragmentation of registered signals. Pieces of adequate length (length of window) are cut out of overall current and potential signals. At this point, the whole measured signal can be cut into equal pieces or some specific pieces can be separated by time intervals where the registered data are not treated at all. As the lengths of time windows are much shorter than the whole measurement time, location in time can be ascribed to each piece. According to one's need, overall and local fragmentation can be applied.

The last step is Fourier transformation of signals inside each time window, from time to frequency domain. On this basis, temporary impedance spectra are available, which are located in time.

\section{Examples of determination of total cell impedance}

Application of the method to an equivalent circuit

\section{Experimental setup}

In order to apply the authors' procedure in a more practical manner, an equivalent circuit model was utilized. Figure 2 illustrates a model that consists of two electrical equivalent circuits coupled with a single resistor $R_{3}$. The model is a simple electrical analog of non-stationary two-electrode configuration which generally describes an electrochemical cell. A nonstationary element was introduced by applying resistance parameters $R_{1}$ and $R_{2}$ dependent on operating time. Values of both $R_{1}$ and $R_{2}$ elements change linearly with time. In the case of $R_{1}$, changes in resistance values from approximately $0 \Omega$ up to $10 \mathrm{k} \Omega$ were obtained at a speed rate $\mathrm{d} R / \mathrm{d} t$ equal to $0.5 \Omega / \mathrm{s}$, while changes in $R_{2}$ values were acquired from values close to $10 \mathrm{k} \Omega$ up to $0 \Omega$ at $-0.5 \Omega / \mathrm{s}$, respectively. Resistance characteristics were obtained throughout the experiment by employing a dual digital potentiometer DS1267-10.

The measurement of impedance in a galvanostatic manner was performed using the system based on potentiostat/galvanostat Autolab pgstat30 and data acquisition card National Instruments PXI6120 which was described in detail previously $[46,47]$. Its original configuration involved a two-electrode 
Fig. 2 Electrical diagram of the studied system with programmed resistance changes. $R_{1}, R_{2}$-resistors with resistance change programmed in time, $C_{1}=1 \mu \mathrm{F}, C_{2}=10 \mu \mathrm{F}$, $R_{3}=120 \Omega$
$Z_{\mathrm{AD}}(j \omega)$

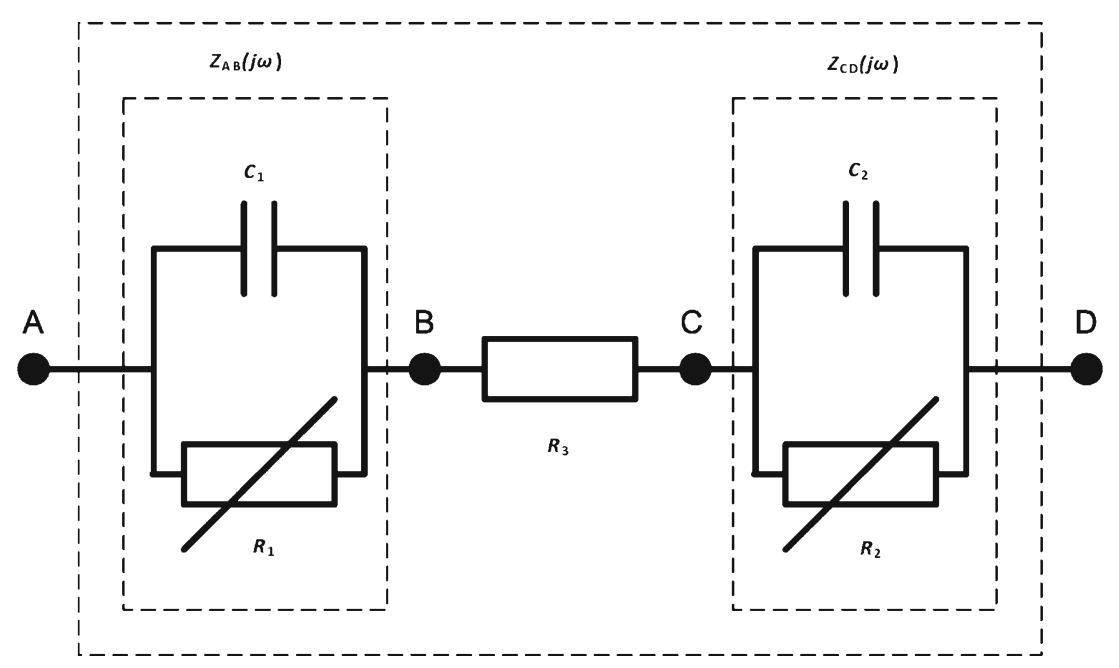

system, i.e., the current flow which was a multisinusoidal signal was passed throughout the entire system (Fig. 2).

The whole measurement time interval was $2,000 \mathrm{~s}$, which was caused by the speed of changes in $R_{1}$ and $R_{2}$. The signals were registered with sampling frequency of $f_{\mathrm{s}}=$ $12.5 \mathrm{kHz}$ that causes restriction of maximal frequency, according to Nyquist law, which cannot exceed $6.5 \mathrm{kHz}$. In this study, $f_{\max }$ was equal to $4.5 \mathrm{kHz}$. All of the registered signals were cut into windows with equal length of $100 \mathrm{~s}$. It determines the minimal value of frequencies: $f_{\min }>=\Delta f=$ $0.01 \mathrm{~Hz}$. In this study, $f_{\min }$ was equal to $0.07 \mathrm{~Hz}$. Correspondingly, all imposed frequencies, presented in Table 1, were taken as multiples/product of this fundamental frequency and prime numbers.

Amplitudes of the excitation signal's components were picked up in a way that provides good detection of potential response signals. Keeping in mind that (a) for most systems, impedance decreases when frequency increases and (b) the amplitude of response potential signal is directly proportional to impedance; applied amplitudes of current excitation signals decrease with frequency of component. For low frequencies, this trend was inversed (Table 1). It was connected with the character of Fourier transformation: the lower the frequency, the less periods are submitted to averaging, which has direct influence on the precision of results. When choosing amplitudes, one should afford to keep the resultant amplitude of multisinusoidal excitation signal at the lowest possible level. Proper adjustment of phase shift of every component is helpful. During preparation of excitation signal, Schroeder relation was used [48, 49]:

$$
\begin{aligned}
\phi_{k n} & =\phi_{k n-1}+2\left(k_{n}-k_{n-1}\right) \sum_{m=1}^{n_{\max }-1} p_{k m} \\
n & =2, \ldots, n_{\max }
\end{aligned}
$$

where $\Phi_{\mathrm{kn}}$ is the remaining phase angles, $k_{\mathrm{n}}$ is the harmonic number, and $p_{\mathrm{km}}$ is the relative power of harmonic.
Table 1 Frequencies, phases, and amplitudes of multisinusoidal exci-

\begin{tabular}{|c|c|c|}
\hline Frequency $(\mathrm{Hz})$ & Phase (deg) & Amplitude (uA) \\
\hline 0.07 & 359 & 0.16 \\
\hline 0.11 & 0.2304 & 0.15 \\
\hline 0.17 & 0.3456 & 0.15 \\
\hline 0.29 & 0.6912 & 0.125 \\
\hline 0.43 & 0.8064 & 0.12 \\
\hline 0.71 & 1.6128 & 0.125 \\
\hline 1.13 & 2.4192 & 0.135 \\
\hline 1.79 & 3.8016 & 0.14 \\
\hline 2.81 & 5.8752 & 0.15 \\
\hline 4.43 & 9.3312 & 0.16 \\
\hline 7.09 & 15.3216 & 0.165 \\
\hline 11.23 & 23.8464 & 0.175 \\
\hline 17.77 & 37.6704 & 0.18 \\
\hline 28.19 & 60.0192 & 0.2 \\
\hline 44.81 & 95.7312 & 0.205 \\
\hline 71.03 & 151.027 & 0.21 \\
\hline 112.73 & 240.192 & 0.24 \\
\hline 178.81 & 20.6208 & 0.25 \\
\hline 283.51 & 243.072 & 0.255 \\
\hline 450.07 & 239.386 & 0.275 \\
\hline 569.99 & 330.739 & 0.29 \\
\hline 710.39 & 88.704 & 0.295 \\
\hline 920.83 & 132.134 & 0.3 \\
\hline $1,127.41$ & 109.901 & 0.3 \\
\hline $1,501.07$ & 352.282 & 0.325 \\
\hline $1,788.17$ & 213.696 & 0.34 \\
\hline $2,333.29$ & 259.891 & 0.345 \\
\hline $2,835.11$ & 10.4832 & 0.35 \\
\hline $4,500.01$ & 229.824 & 0.35 \\
\hline
\end{tabular}
tation signal 
As a result of this operation, amplitudes and phases of the excitation signal's components were selected in a way to make sure that voltage response signal does not exceed $24 \mathrm{mV}$ peak to peak (the difference between maximal and minimal amplitude of altering signal inside an analyzing window).

The voltage signal between points $\mathrm{A}$ and $\mathrm{D}$ was registered. Additionally, voltage signals between points A and B and points $\mathrm{C}$ and $\mathrm{D}$ were acquired simultaneously. In order to acquire instantaneous impedance spectra, time registers were treated with the use of STDFT transform when the length of the window analysis was equal to $100 \mathrm{~s}$. In this time interval, all frequencies of multisinusoidal excitation signal have a complete number of periods. Inside each time window, the oscillations of all frequencies have integer numbers of complete periods. In the case presented here, the analyzing window was seven times longer than the period of the lowest frequency. It was possible due to slow changes of resistances $R_{1}$ and $R_{2}$ and had beneficial influence on the quality of results (accuracy increases with the number of periods analyzed with Fourier transformation). The analysis of experimental impedance spectra was conducted using the ZSimpWin correlation program register.

\section{Results}

The transformation of the current and voltage registers, acquired between points $\mathrm{A}$ and $\mathrm{D}$, enables the obtainment of a global impedance description of a two-electrode system $Z_{A D}(j, t)=f\left[U_{A-D}(, t), I_{A-D}(, t)\right]$. The changes of the impedance values in time are presented in Fig. 3.
The impedance spectra of a global two-electrode system generally take the form of two semicircles. The first semicircle, which undergoes detection within the range of higher frequencies, represents the $Z_{\mathrm{AB}}(j \omega)$ impedance values which increase throughout the operating time. The second semicircle that was detected in the low frequency range at the initial stage of the investigation represents impedance values $Z_{\mathrm{CD}}(j \omega)$.

Analysis of impedance data of the system where two or more electrical elements or equivalent circuits are connected in a series causes some difficulties. Use of algorithms by which impedance spectra are analyzed does not allow the differentiation into an order of the elements in series. Permutation of these elements in series does not alter anything. It is particularly crucial when two-electrode systems such as power cells are investigated. In such a situation, one needs to deal with two impedance values of the elements in series. Relaying on electrical parameters obtained as a result of fitting an equivalent electrical circuit to experimental data is not reliable enough to attribute obtained resistance or capacitance values to exact (correct) electrode.

A similar situation also occurs in the case of a model system that includes two time constants that are related to electrical circuits RC coupled in series (Fig. 2). Figure 4 illustrates $R_{1}, R_{2}$ and $C_{1}, C_{2}$ values as a function of time. These electrical parameters are obtained as a result of fitting experimental data to equivalent electrical circuit (Fig. 3). The knowledge of the electrical model allows estimation that the calculated values presented in Fig. 4 might correspond to $R_{1}$ and $R_{2}$ as well as $C_{1}$ and $C_{2}$, respectively. Thus, it is impossible to decide if the acquired resistance or
Fig. 3 Changes of the impedance of a global twoelectrode system versus time for the assumed changes of the first and the second electrode

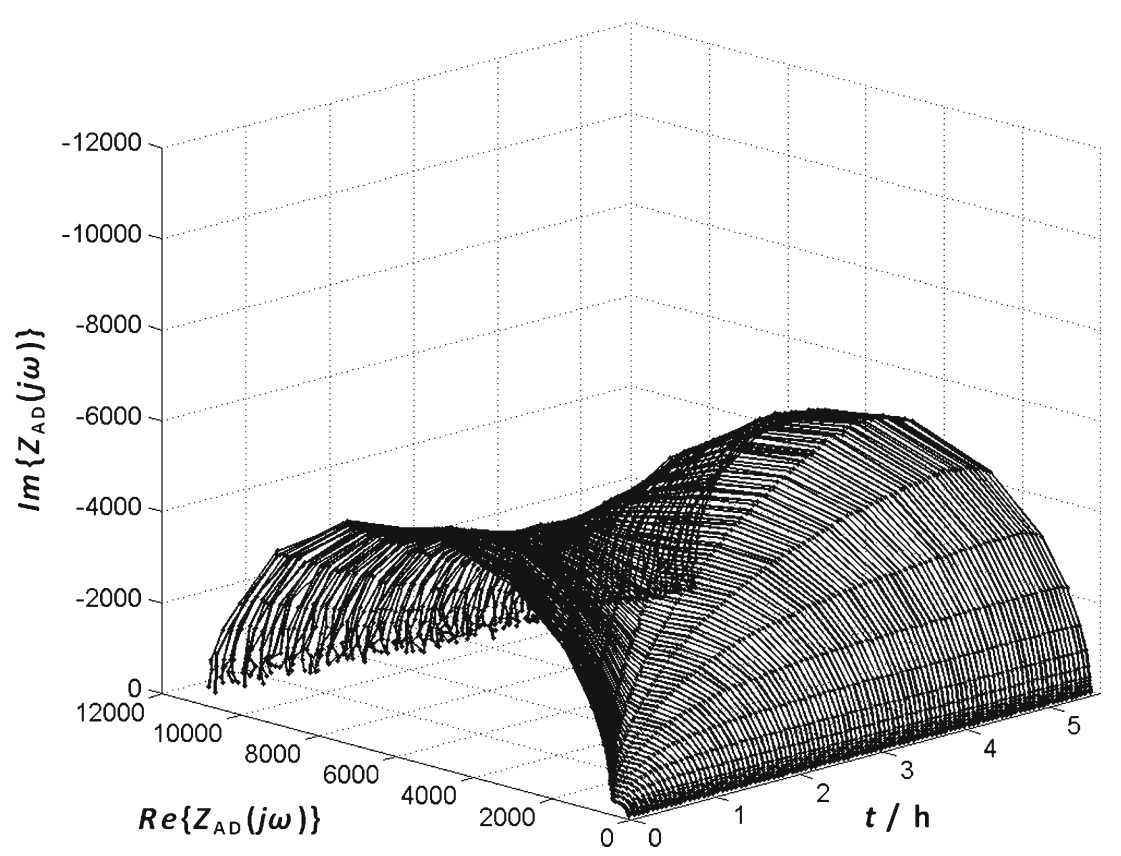




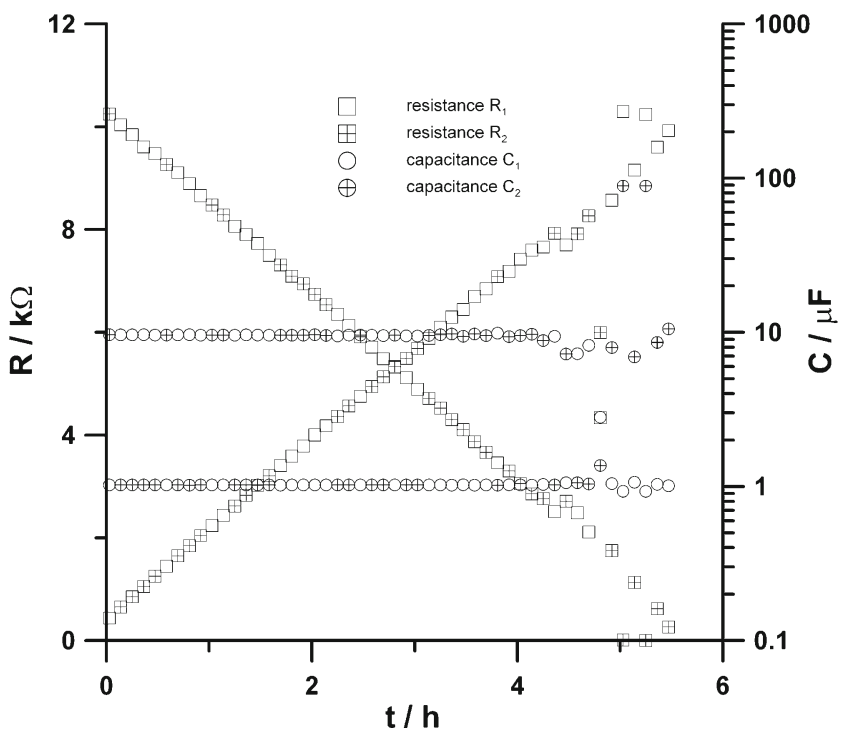

Fig. 4 Evolution of the resistance values, $R_{1}$ (open square) and $R_{2}$ (square with cross), and the capacitance values, $C_{1}$ (open circle) and $C_{2}$ (square with cross), vs. operating time, obtained as a result of fitting impedance data representing the entire system

capacitance values represent the first or the second time constant. After $5 \mathrm{~h}$ of measurement, there is a noticeable large scatter of the obtained results. At this time of the experiment, the difference between impedance results which were analyzed by two different electrical circuits is significant. Moreover, impedance changes of those equivalent circuits remained in the same frequency range. All of these lead to a conclusion that the results obtained as a result of analysis were burdened with some high error and hence were questionable.
It is possible to gain adequate results by analysis of impedance spectra illustrating the impedance values of each electrode individually. Thus, such impedance spectrum could be obtained during the investigation on the condition that two additional voltage registers are acquired (Figs. 5 and 6).

$$
\begin{aligned}
Z_{A B}(j, t) & =f\left[U_{A-B}(, t), I_{A-D}(, t)\right] \\
Z_{C D}(j, t) & =f\left[U_{C-D}(, t), I_{A-D}(, t)\right]
\end{aligned}
$$

The analysis of impedance spectra resulting in partial impedances of the studied system provides accurate results within the entire range. Figure 7 presents changes of the resistance and the capacitance values of the left and right electrodes determined on the basis of the analysis of the experimental time diagram of impedance. The slope of the resistance curves are identical as programmed change rate equal to $\mathrm{d} R_{1} / \mathrm{d} t=$ $0.5 \Omega / \mathrm{s}$ and $\mathrm{d} R_{2} / \mathrm{d} t=-0.5 \Omega / \mathrm{s}$. An adequate situation takes place in the case of $C_{1}$ and $C_{2}$. Once more, an analysis of partial impedance values allows the provision of adequate capacitance values.

\section{Real cell}

Apart from analysis of the circuit model, the proposed technique was applied to direct methanol fuel cell (DMFC). The in situ impedance measurements of fuel cell are usually conducted in a two-electrode configuration because placing a reference electrode inside a fuel cell is a challenge, especially in the case of solid electrolytes [50]. In the measurement of a two-electrode configuration, the
Fig. 5 Changes of the impedance of the left electrode $Z_{\mathrm{AB}}(j \omega)$ during the experiment

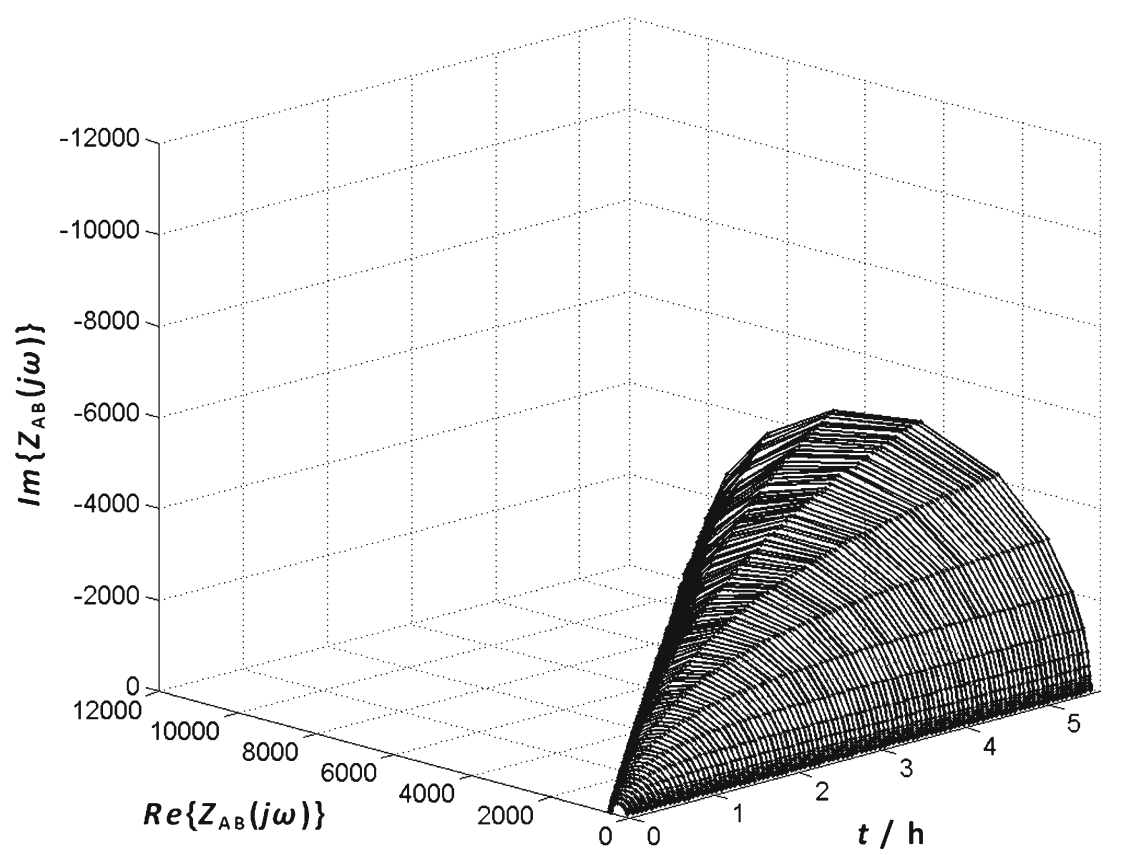


Fig. 6 Changes of the impedance of the right electrode $Z_{\mathrm{CD}}(j \omega)$ during the experiment

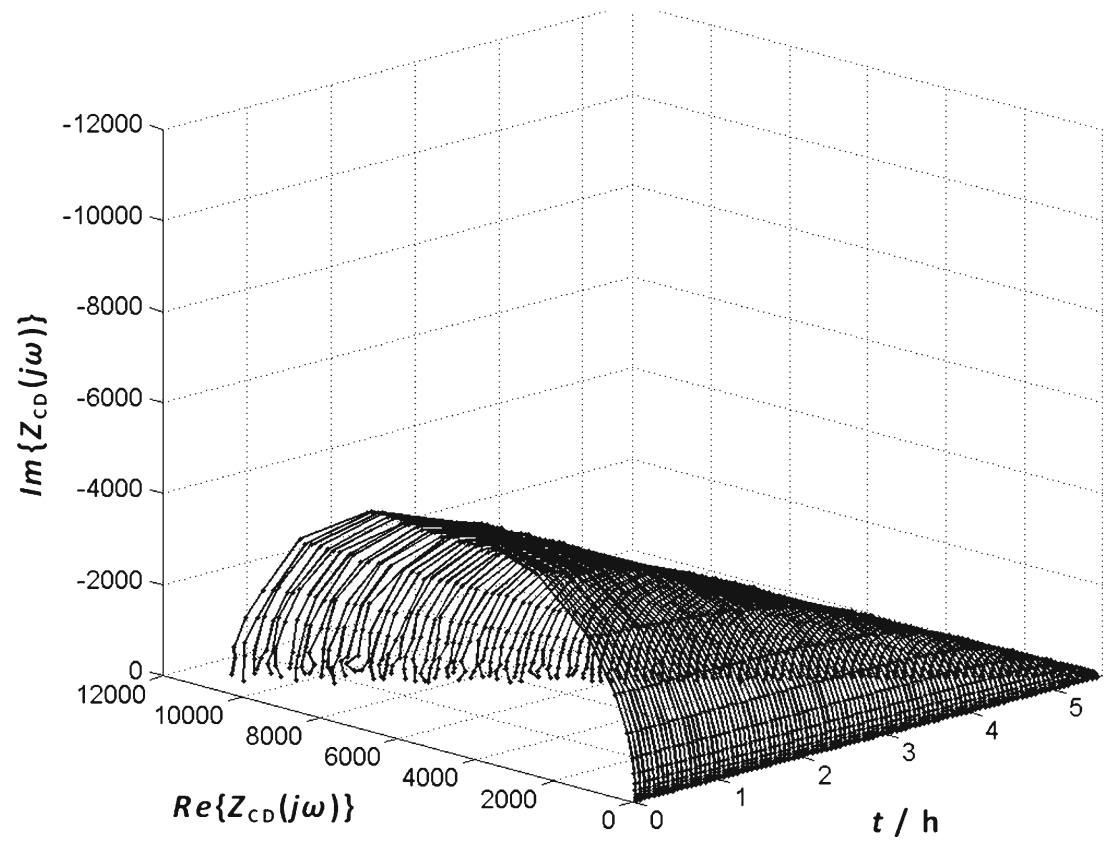

impedance of individual electrodes cannot be obtained directly. Fortunately, if the anode side with $\mathrm{Pt}$ as catalyst is fed with hydrogen stream to become a reversible hydrogen electrode, only the impedance of cathode processes is measured [51]. It is also possible to obtain the individual behavior of the anode and cathode by using symmetrical single cells operated with an identical hydrogen or oxygen supply in both compartments. However, the measurement has to be conducted at open circuit voltage [52]. J. T. Mueller et al. and Lai et al.

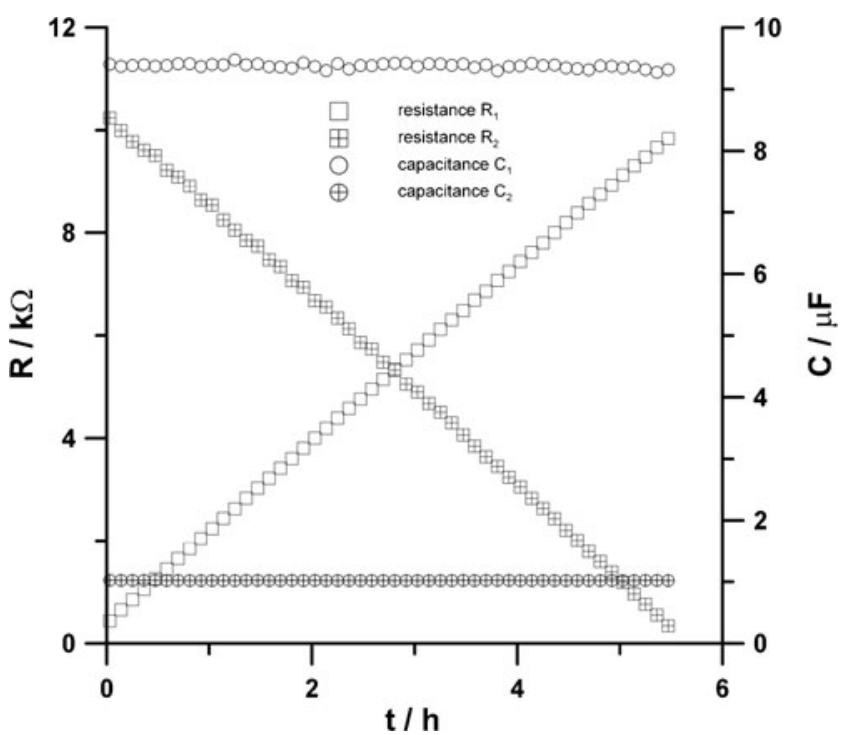

Fig. 7 Changes of the resistance values, $R_{1}$ (open square) and $R_{2}$ (square with cross), and the capacitance values, $C_{1}$ (open circle) and $C_{2}$ (square with cross), determined on the basis of the analysis of impedance diagram of the left and the right electrodes have obtained impedance characteristics of anodes by applying the EIS technique in a two-electrode configuration when cathode was operated on hydrogen instead of oxygen or air $[14,53,54]$. To measure the individual contributions from the cathode and the anode of the polymer electrolyte membrane fuel cell, the reference electrode must either be in direct contact with proton exchange membrane or be located in a separate compartment with electrical contact provided by salt bridge with solid membrane [55]. Yang et al. developed a three-electrode EIS measurement to characterize a direct methanol fuel cell under various operating conditions. A silver/silver chloride electrode was used as an external reference electrode $[12,56]$. Gerteisen presented a concept for realizing a reference electrode configuration in a PEMFC by means of laser ablation [57]. Diard et al. used a reference electrode, which was platinum wire, plunged in methanol solution [58]. However, in principle, three- or two-electrode EIS measurement requires conditioning of the fuel cell to ensure stationarity. The changes of the individual impedance spectra of anode and cathode were not obtained at the same time.

\section{Experimental}

The single fuel cell tested in this study had an active area of $1 \mathrm{~cm}^{2}$. The membrane electrolyte assembly consisted of Nafion 115 (thickness $125 \mu \mathrm{m}$ ) loading Pt-Ru of $2.5 \mathrm{mg} /$ $\mathrm{cm}^{2}$ at the anode and Pt of $2.5 \mathrm{mg} / \mathrm{cm}^{2}$ at the cathode. Gas diffusion layer was hydrophobized substrate with a $5 \mathrm{wt} . \%$. Polytetrafluoro-etylene (PTFE) loading at the anode and 10 wt.\% PTFE loading at the cathode, according to 


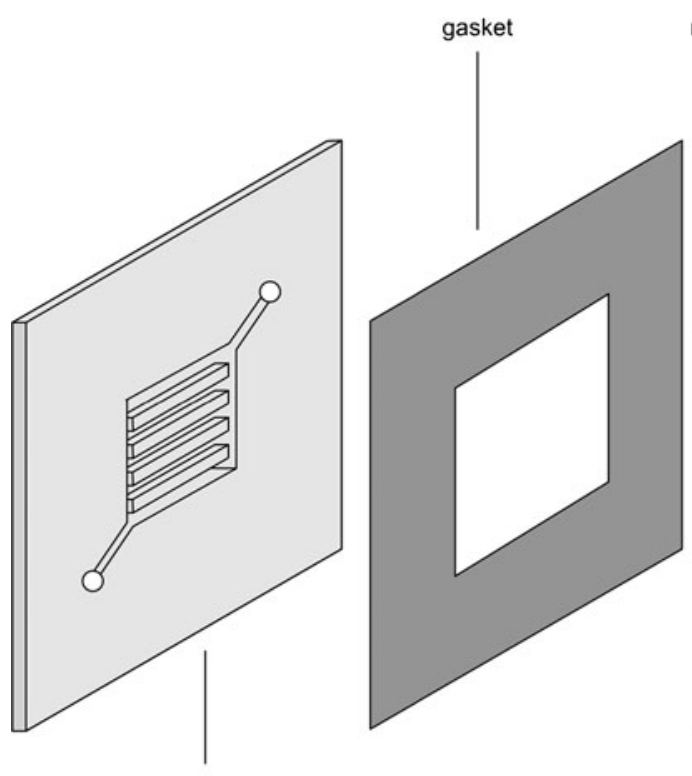

graphite plate
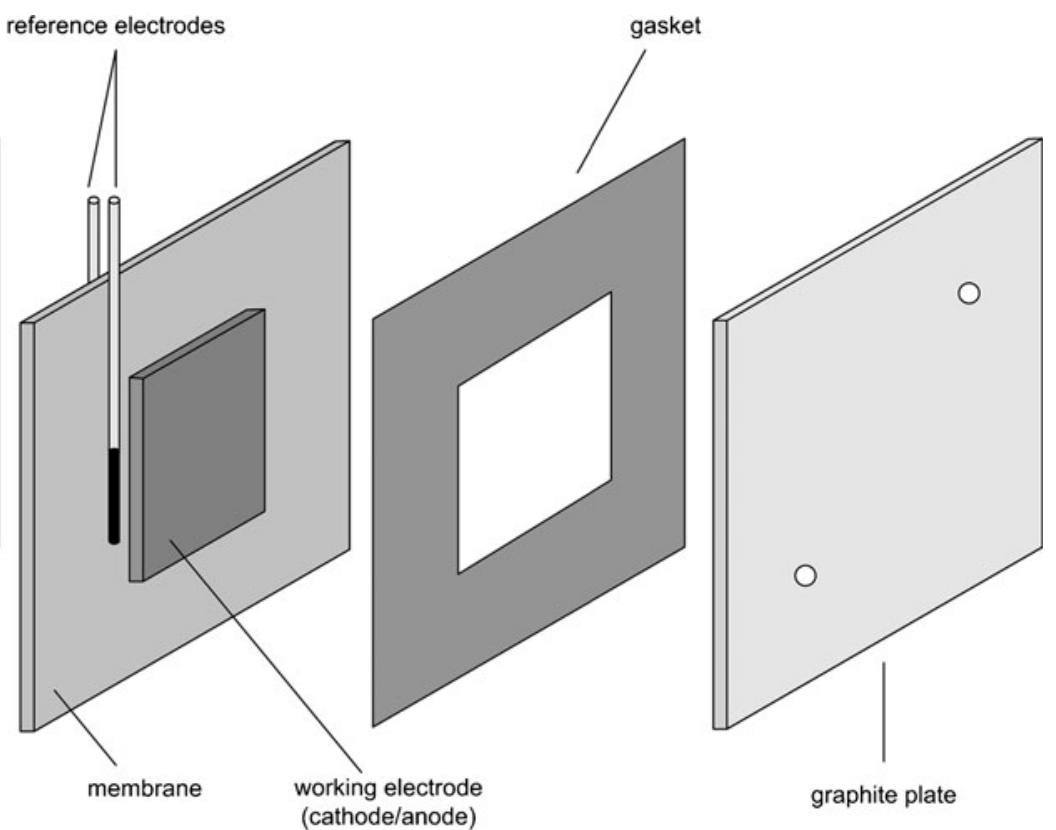

graphite plate

Fig. 8 Schematic presentation of the investigated cell

producers, assure an open pore structure, good mechanical strength, and high electrical conductivity and targeted for use in moderate-to-high humidity and higher current density operating environments. Processing steps to the substrate consist of

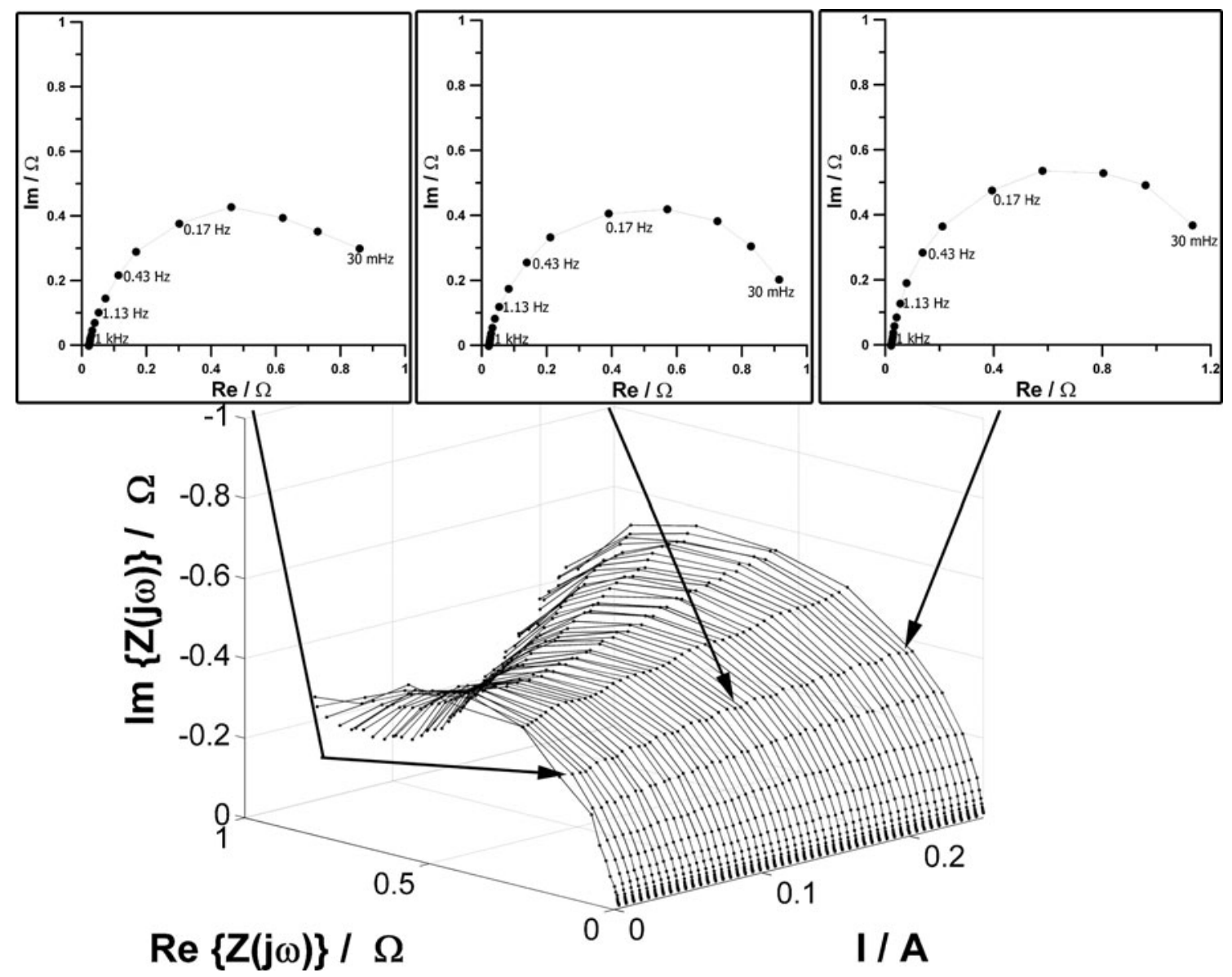

Fig. 9 Change in global cell impedance of DMFC during a change in the cell load 


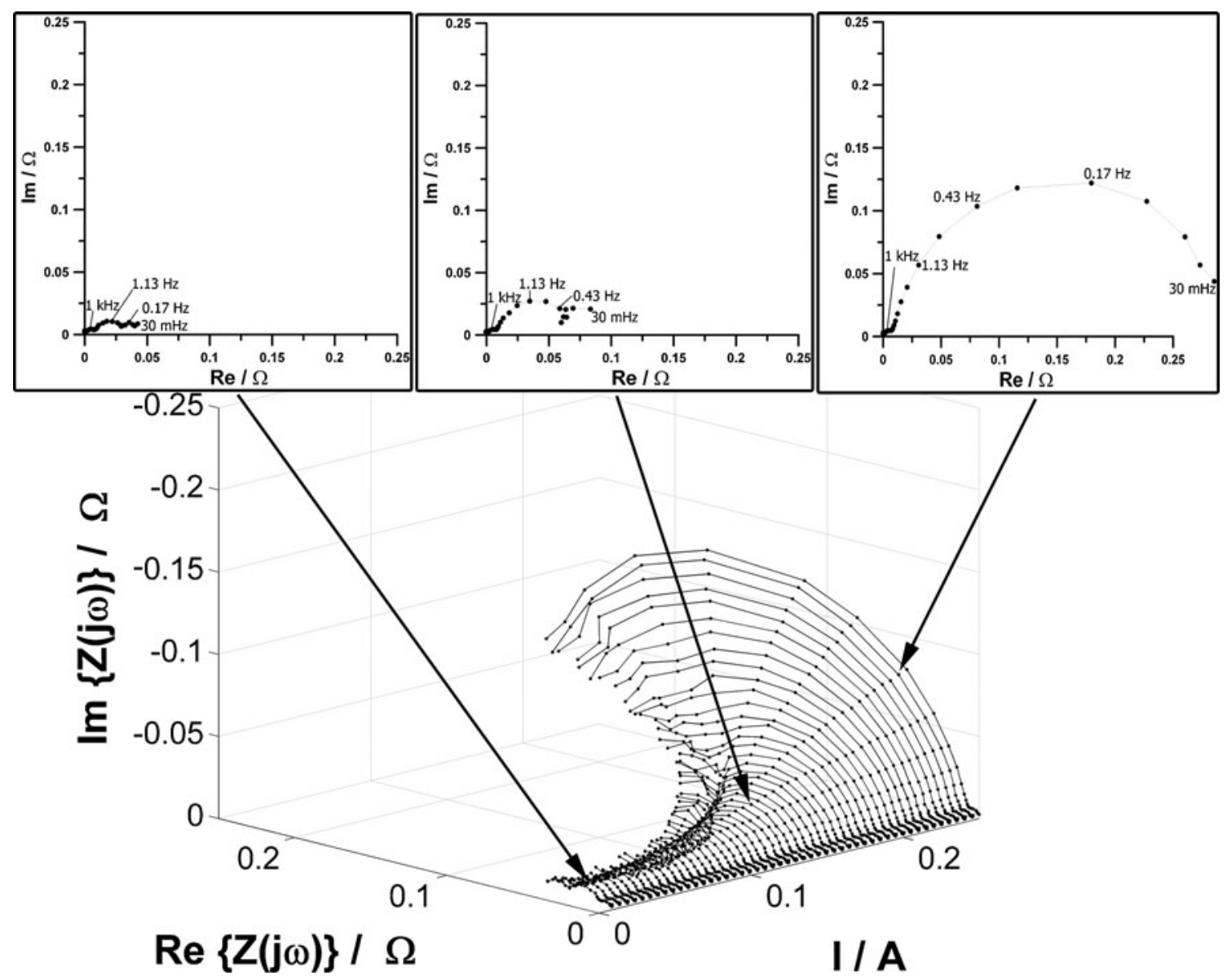

Fig. 10 Change in anode impedance of DMFC during a change in the cell load

bulk impregnation of the standard carbon fiber matrix with PTFE. There were channels with parallel geometry in the graphite plates, $1 \mathrm{~mm}$ in flow field depth and $1 \mathrm{~mm}$ in width. The fuel used at the anode was $3 \mathrm{wt} . \%$ methanol solution. The solution was supplied to the fuel cell via a pump (KNF, Stepdos FEM03_18/RC). Air was used as an oxidant with its flow controlled by a mass flow controller (Brooks MFC 5850E).

To register individual anode's and cathode's potentials, small silver/silver chloride pseudo-reference electrodes, made of silver wire $(\phi=50 \mu \mathrm{m})$ covered with silver chloride, were used. They were placed on both sides of the membrane, without addition of chloride containing electrolyte, opposite to each other, and each was $500 \mu \mathrm{m}$ far from the anode and the cathode, respectively (Fig. 8). These pseudo-reference electrodes were electrically separated from other elements of the cell by non-conducting polyethylene gasket. Due to this isolation, the only electrical contact was possible across the membrane.

One should note that registration of potential between reference electrodes allows for determination of membrane's impedance. In the case described here, this possibility was not utilized. Acquisition card (PXI6120) allows for registration of only four signals simultaneously. Registration of potential between anode and cathode was sacrificed to allow registration of potential between reference electrodes. Impedance of the whole cell could not be registered directly and was calculated as the sum of cathode's, anode's and membrane's impedances.

Karta PXI due to limitation of acquisition card (PXI6120), which can register only four signals simultaneously.

The AC multisinusoidal signal that was applied in order to evaluate impedance values had a similar frequency composition as in the case of analysis with the use of electrical model system (components 50 and $30 \mathrm{mHz}$ were added). Also, the same procedures for choosing amplitudes and phase shifts of each component were used in order to keep the amplitude of AC voltage response signal below $24 \mathrm{mV}$ peak to peak throughout the entire experiment. The length of the analyzing window was $100 \mathrm{~s}$.

In order to get simultaneous and independent characteristics of positive and negative electrode, as well as the entire investigated system, potentials of both electrodes were registered versus pseudo-reference electrodes.

The experiment was conducted at a constant temperature of $75^{\circ} \mathrm{C}$ and at a constant methanol flow equal to $0.11 \mathrm{ml} /$ min, with air flow of $13.5 \mathrm{ml} / \mathrm{min}$. Measurements were performed in a galvanodynamic manner with a linear load change at a rate equal to $0.003 \mathrm{~mA} / \mathrm{s}$. 
Figure 9 presents a change of the cell impedance value during operation along with a changing load. The highest impedance values are observed for the highest load of the fuel cell. An initial increase of the load, up to $100 \mathrm{~mA}$, decreases the impedance values. In the Nyquist diagram, the lowest impedance values are obtained at around $100 \mathrm{~mA}$ with the value of impedance increasing consistently with the increase in the load afterwards. Using only the impedance characteristic of fuel cell, it is difficult to diagnose the limiting process in a fuel cell during the real operation. When conducting individual electrode impedance measurements, it is necessary to place a pseudo-reference electrode inside a fuel cell. Information obtained separately at the anode and the cathode helps to identify problems in the fuel cell.

Figure 10 presents changes in anodic impedance of DMFC during a change in the cell load. It is visible that impedance increases with the increase of the load. Initially, impedance characteristics increase only slightly, until the load is close to $100 \mathrm{~mA}$, with a very rapid increase of the impedance for higher values. Up to the load of approximately $150 \mathrm{~mA}$, impedance diagrams consist of three partial semicircles, and for higher values two semicircles are visible on the Nyquist plots. Moreover, all temporary impedance spectra start almost in the beginning of coordinate system, which is the result of the negligible membrane's surface resistance between pseudo-reference electrode and anode.

Figure 11 presents a change in cathode impedance of DMFC during cell load. The highest impedance values of the cathode are observed for the lowest load of the fuel cell. With the increase in the load, the impedance values become reduced.

The values of electrode impedance depend on the value of load of the fuel cell. It suggests that this characteristic is determined either by the cathode or by both electrodes, depending on the power consumption value. Similarly as in the anodic spectra, here the spectra start closely to the beginning of the coordinate system.

\section{Conclusions}

The presented measurement methodology has proven to have some potential in the comprehensive impedance analysis of an electrochemical system:

- The simultaneous impedance measurements of cathode, anode, and global system measurement provide results consistent with the real values.

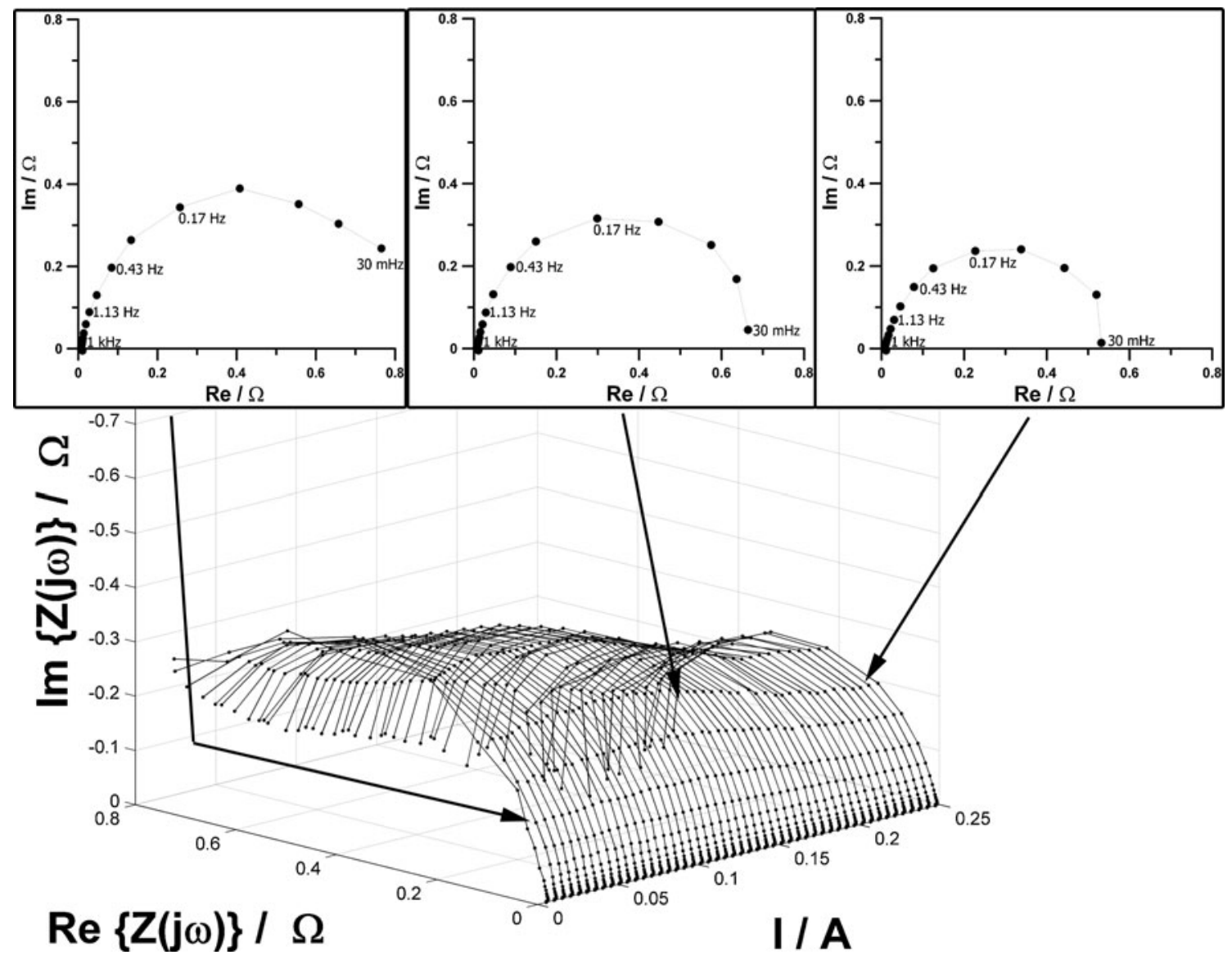

Fig. 11 Change in cathode impedance of DMFC during a change in the cell load 
- The technique can be used for monitoring the cell during real operation.

- The impedance characteristics of each cell component can be obtained at the same time, allowing for measurement of the impedance of both positive and negative electrodes as well as the entire investigated system simultaneously.

- The method can be used for monitoring the state of chargedischarge of electrochemical cells and individual electrodes' contributions to the overall performance of the cell.

- The method can be used for optimizing the operating conditions of the fuel cells.

The new measurement methodology proved to be a useful tool in the study of two-electrode configuration systems such as secondary cells, supercapacitators, fuel cells, etc., whose performance depends on reactions taking place on both positive and negative electrodes.

Acknowledgments This research was supported by a grant financed by the Polish Ministry of Education and Science, NR05 006506.

Open Access This article is distributed under the terms of the Creative Commons Attribution License which permits any use, distribution, and reproduction in any medium, provided the original author(s) and the source are credited.

\section{References}

1. Jang JH, Han S, Hyeon T, Oh SM (2003) J Power Sources 123:79-85

2. Chen QL, Shen W, Tao FF, Yin SY, Xu W (2004) Electrochim Acta 49:4157-4161

3. Horvat-Radosevic V, Kvastek K, Vukovic M, Cukman D (2000) J Electroanal Chem 482:188-201

4. Chun SE, Pyun SI, Lee GJ (2006) Electrochim Acta 51:6479-6486

5. Sauvant-Moynot V, Bernard J, Mingant R, Delaille A, Mattera F, Mailley S, Hognon JL, Huet F (2010) Oil Gas Sci TechnolRev Inst Fr Pet 65:79-89

6. Zhang YC, Wang CY (2009) J Electrochem Soc 156:A527-A535

7. Karden E, Buller S, De Doncker RW (2000) J Power Sources 85:72-78

8. Robinson RS (1996) On-line battery testing: a reliable method for determining battery health. 18th Telecommunications Energy Conference, INTELEC' 96, October 06-10, 1996 Boston, p. 654

9. Zhang SS, Xu K, Jow TR (2004) Electrochim Acta 49:1057-1061

10. Oedegaard A (2006) J Power Sources 157:244-252

11. Seo SH, Lee CS (2008) Energy Fuel 22:1204-1211

12. Yang SH, Chen CY, Wang WJ (2010) J Power Sources 195:2319-2330

13. Amphlett JC, Peppley BA, Halliop E, Sadiq A (2001) J Power Sources 96:204-213

14. Mueller JT, Urban PM (1998) J Power Sources 75:139-143

15. Chakraborty D, Chorkendoff I, Johannessen T (2006) J Power Sources 126:1010-1022

16. Lee HH, Lee KY, Lee JY (1997) J Alloy Compd 260:201-207

17. Kerlau M, Marcinek M, Srinivasan V, Kostecki RM (2007) Electrochim Acta 53:1385-1392

18. Sethuraman VA, Hardwick LJ, Srinivasan V, Kostecki RM (2010) J Power Sources 195:3655-3660

19. Wang HP, Huang HT, Wunder SL (2000) J Electrochem Soc $147: 2853-2861$
20. Takahashi M, Tobishima S, Takei K, Sakurai Y (2002) Solid State Ionics 148:283-289

21. Abraham DP, Poppen SD, Jansen AN, Liu J, Dees DW (2004) Electrochim Acta 49:4763-4775

22. Garnier S, Bohnke C, Bohnke O, Fourquet JL (1996) Solid State Ionics 83:323-332

23. Lee JW, Pyun SI (2004) Electrochim Acta 49:753-761

24. Karden E, Buller S, De Doncke RW (2002) Electrochim Acta 47:2347-2356

25. Kurian M, Galvin ME, Trapa PE et al (2005) Electrochim Acta 50:2125-2134

26. Kleperis J, Wojcik G, Czerwinsk A, Skowronski J, Kopczyk M, Beltowska-Brzezinska M (2001) J Solid State Electrochem 5:229-249

27. Losiewicz B, Budniok A, Rowinski E, Lagiewka E, Lasia A (2004) Int J Hydrogen Energ 29:145-157

28. Lundqvist A, Lindbergh G (1999) Electrochim Acta 44:25232542

29. Tang R, Liu LQ, Liu YN (2003) Int J Hydrogen Energ 28:815-819

30. Xue FQ, Wang YL, Wang WH, Wang XD (2008) Electrochim Acta 53:6636-6642

31. Zhang B, Zhong JH, Li WJ, Dai ZY, Zhang B, Cheng ZM (2010) J Power Sources 195:4338-4343

32. Mengarda P, Impinnisi PR (2009) J Power Sources 191:28-35

33. Creason SC, Smith DE (1972) J Electroanal Chem 36: App1-App7

34. Creason SC, Smith DE (1972) J Electroanal Chem 40:1-5

35. Creason SC, Smith DE (1973) Anal Chem 45:2401-2403

36. Popkirov GS (1996) Electrochim Acta 41:1023-1027

37. Hazi J, Elton DM, Czerwinski WA, Schiewe J, Vincente-Beckett VA, Bond AM (1997) J Electroanal Chem 437:1-15

38. Rosvall M (2000) Electrochem Commun 2:338-343

39. Garland JE, Pettit CM, Roy D (2004) Electrochim Acta 49:2623-2635

40. Sher AA, Bond AM, Gavaghan DJ, Gillow K, Duffy NW, Guo SX, Zhang J (2005) Electroanalysis 17:1450-1462

41. Seland F, Tunold R, Harrington DA (2008) Electrochim Acta 53:6851-6864

42. Ingelgem YV, Tourwe E, Blajiev O, Pintelon R, Hubin A (2009) Electroanalysis 21:730-739

43. Ragoisha GA, Osipovich NP, Bondarenko AS, Zhang J, Kocha S, Iiyama A (2010) J Solid State Electrochem 14:531-542

44. Qian S, Chen D (1996) Joint time-frequency analysis, methods and applications. Prentice Hall, Englewood Cliffs

45. Carmona R, Hwang W, Torresani B (1998) Practical time-frequency analysis. Academic, San Diego

46. Slepski P, Darowicki K, Andrearczyk K (2009) J Electroanal Chem 633:121-126

47. Slepski P, Darowicki K, Kopczyk M, Sierczynska A, Andrearczyk K (2010) J Power Sources 195:2457-2462

48. Van Greem E, Vereecken J, Schoukens J, Pintelon R, Guillaume P, Verboven P, Pauwels L (2004) Electrochim Acta 49:2919-2925

49. Van Den Bos A (1987) IEEE Trans Acoust Speech Sig Process ASSP-35:120-122

50. O’Hayre R, Prinz FB (2004) J Electrochem Soc 151:A756-A762

51. Springer TE, Zawodzinski TA, Wilson MS, Gottesfeld S (1996) J Electrochem Soc 143:587-599

52. Wagner N (2002) J Appl Electrochem 32:859-863

53. Lai CM, Lin JC, Hsueh KL, Hwang CP, Tsay KC, Tsai LD, Peng YM (2007) Int J Hydrog Energy 32:4381-4388

54. Muller JT, Urban PM, Holderich WF (1999) J Power Sources $84: 157-160$

55. Foulkes FR, Archibald GW, Ogumi Z, Takehara Z (1990) J Electrochem Soc 137:2022-2024

56. Yang SH, Chen CY, Wang WJ (2010) J Power Sources 195:35363545

57. Gerteisen D (2007) J Appl Electrochem 37:1447-1454

58. Diard JP, Glandut N, Landaud P, LeGorrec B, Montella C (2003) Electrochim Acta 48:555-562 